\title{
Syphilis. Diagnostic and therapeutic recommendations of the Polish Dermatological Society. Part 2: neurosyphilis, syphilis in pregnancy and congenital syphilis
}

\author{
Kiła. Rekomendacje diagnostyczno-terapeutyczne Polskiego Towarzystwa \\ Dermatologicznego. Część 2: kiła układu nerwowego, kiła u kobiet w ciąży \\ oraz kiła wrodzona
}

Anna Wojas-Pelc', Maciej Pastuszczak', Agnieszka B. Serwin², Iwona Rudnicka³, Sławomir Majewski ${ }^{3}$, Rafał Czajkowski ${ }^{4}$ Iwona Flisiak², Waldemar Placek ${ }^{5}$, Joanna Maj ${ }^{6}$, Romuald Maleszka ${ }^{7}$, Lidia Rudnicka ${ }^{8}$

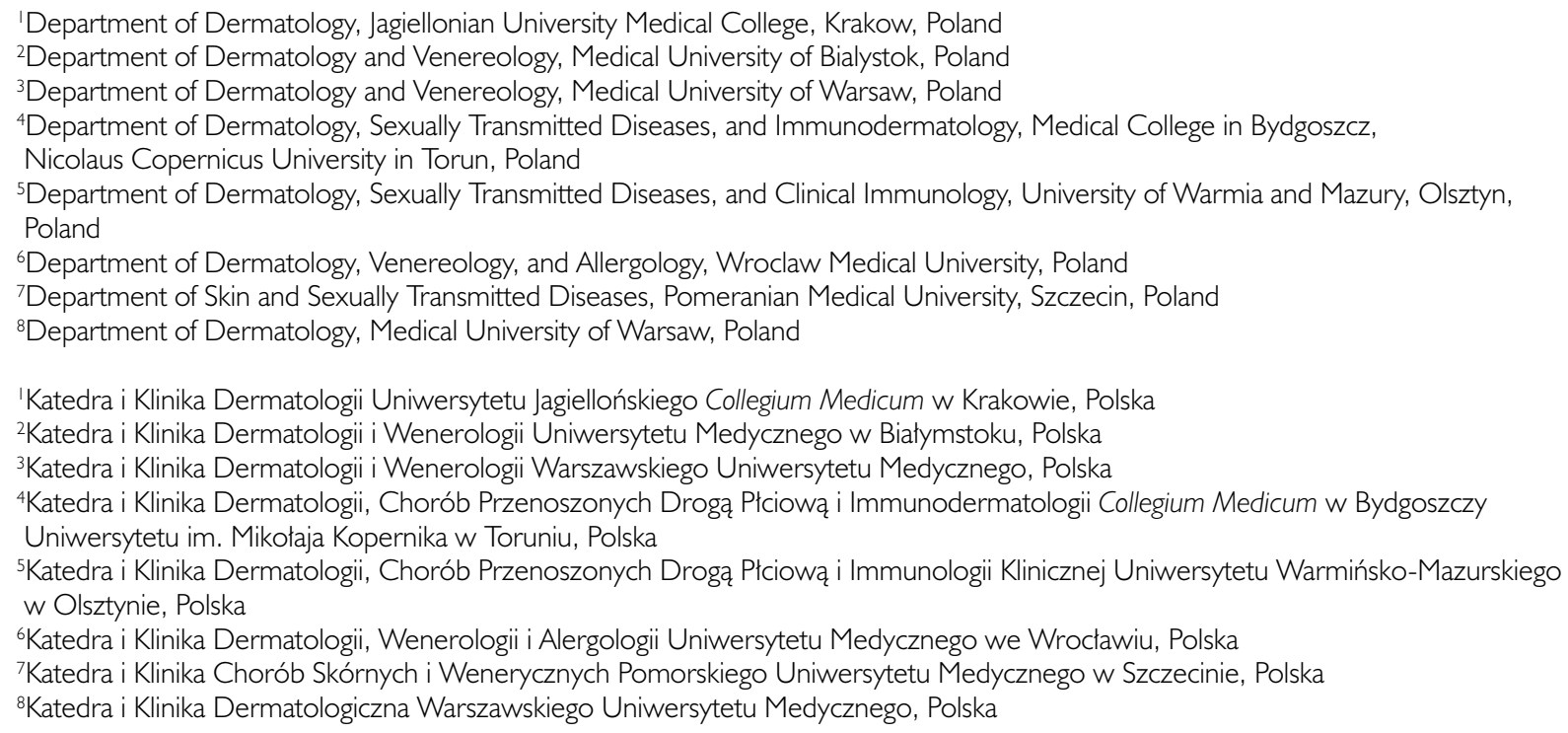

\section{CORRESPONDING AUTHOR/} ADRES DO KORESPONDENCJI:

prof. dr hab. med. Anna Wojas-Pelc Katedra i Klinika Dermatologii Uniwersytet Jagielloński

Collegium Medicum

ul. Skawińska 8

31-066 Kraków

tel./faks: +481243052 66,

wew. 7400

e-mail: wojaspelca@su.krakow.pl

\begin{abstract}
Syphilis (lues) is a systemic bacterial disease transmitted mainly by sexual contacts and caused by Treponema pallidum subsp. pallidum. Due to its numerous symptoms, including various cutaneous and mucosal manifestations, diagnosis and treatment should be performed by dermatology and venereology experts. The incidence of syphilis has been increasing in the last years and syphilis has become a significant epidemiological problem in contemporary medicine. Contrary to a number of other infectious diseases, etiological agents of syphilis have never been cultured. Thus, diagnostic standards are based on indirect methods, such as serological tests. They are also used for monitoring treatment efficacy. Parenteral penicillin remains the gold standard in therapy of syphilis. Part 2 of recommendations discusses in detail clinical presentation, diagnostics, and treatment of neurosyphilis, syphilis in pregnancy and congenital syphilis.
\end{abstract}




\section{STRESZCZENIE}

Kiła (syphilis, lues) jest układową chorobą bakteryjną przenoszoną głównie poprzez kontakty seksualne, wywołaną przez krętka bladego (Treponema pallidum subsp. pallidum). Ze względu na bogatą symptomatologię obejmującą skórę oraz błony śluzowe diagnostyka i leczenie kiły powinny pozostawać w kompetencjach specjalistów z zakresu dermatologii i wenerologii. Częstość zachorowań na kiłę od kilku lat stale się zwiększa, co powoduje, że choroba jest istotnym problemem epidemiologicznym współczesnej medycyny. W przeciwieństwie do wielu innych chorób zakaźnych, dotychczas nie opracowano metod hodowli czynnika etiologicznego kiły. Standardem diagnostycznym są metody pośrednie, takie jak odczyny serologiczne. Testy serologiczne wykorzystywane są również w monitorowaniu efektów leczenia. Złotym standardem terapeutycznym $\mathrm{w}$ kile jest podawana parenteralnie penicylina. W części drugiej rekomendacji szczegółowo omówiono obraz kliniczny, postępowanie diagnostyczne i lecznicze kiły układu nerwowego, kiły u kobiet w ciąży oraz kiły wrodzonej.

Key words: syphilis, recommendation, Polish Dermatological Society. Słowa kluczowe: kiła, rekomendacje, Polskie Towarzystwo Dermatologiczne.

\section{CENTRAL NERVOUS SYSTEM SYPHILIS}

\section{Diagnostics}

There is no one diagnostic test that would allow for diagnosing central nervous system (CNS) syphilis. The diagnosis is made on the basis of clinical presentation and cerebrospinal fluid laboratory test results $[1,2]$.

Every syphilitic patient, regardless of the time period of the infection, should have their detailed history taken for identification of neurological, psychiatric, ophthalmic and laryngological symptoms. Table 1 presents clinical symptoms that require specialist consultations [2-4].

Indications for examination of cerebrospinal fluid in patients with syphilis are being discussed. Most of the experts claim that this examination should absolutely be performed in patients with neurological, psychiatric, ophthalmic or laryngological symptoms. However, it has recently been observed that CNS syphilis may be characterized by scarce neurological and/or psychiatric symptoms [4-6].

Table 2 summarizes indication for cerebrospinal fluid tests in patients with syphilis [3-6].

Available research results in cases of cerebrospinal fluid tests do not allow for acknowledging RPR, USR and other nontreponemal tests as equal to VDRL. Hence, a recommended nontreponemal test for cerebrospinal fluid is only a VDRL test [7, 8] (table 3).

\section{KIŁA OŚRODKOWEGO UKŁADU NERWOWEGO}

\section{Diagnostyka}

Nie ma jednego testu diagnostycznego umożliwiającego ustalenie rozpoznania kiły ośrodkowego układu nerwowego (OUN). Diagnozę stawia się na podstawie obrazu klinicznego i wyników badań laboratoryjnych płynu mózgowo-rdzeniowego [1, 2].

U każdego pacjenta z kiłą, niezależnie od okresu zakażenia, należy przeprowadzić szczegółowy wywiad w kierunku objawów neurologicznych, psychiatrycznych, okulistycznych i laryngologicznych. W tabeli 1 przedstawiono objawy kliniczne, które wymagają konsultacji specjalistycznych [2-4].

Wskazania do badania płynu mózgowo-rdzeniowego u pacjentów z kiłą są przedmiotem dyskusji. Większość ekspertów stoi na stanowisku, że badanie to bezwzględnie należy wykonać $\mathrm{u}$ chorych $\mathrm{z}$ objawami neurologicznymi, psychiatrycznymi, okulistycznymi lub laryngologicznymi. W ostatnim czasie zwraca się jednak uwagę, że kiła OUN może charakteryzować się skąpymi objawami neurologicznymi i/lub psychiatrycznymi [4-6].

$\mathrm{W}$ tabeli 2 podsumowano wskazania do badania płynu mózgowo-rdzeniowego u pacjentów z kiłą [3-6].

Dostępnie wyniki badań w przypadku płynu mózgowo-rdzeniowego nie pozwalają uznać odczynów RPR, USR i innych niekrętkowych za równoważne z VDRL. Dlatego zalecanym odczynem niekrętko- 
Table I. Neurological, ophthalmic and laryngological symptoms in syphilitic patients that require detailed diagnostics

\begin{tabular}{|c|c|c|c|}
\hline Neurological symptoms & Psychiatric symptoms & Ophthalmic symptoms & Laryngological symptoms \\
\hline $\begin{array}{l}\text { - Persistent headaches, } \\
\text { especially in the mornings, } \\
\text { and connected with nausea } \\
\text { and emesis } \\
\text { - Imbalance } \\
\text { - Sensory disorders }\end{array}$ & - Rapidly pregressive dementia & $\begin{array}{l}\text { - Sudden loss of vision, } \\
\text { including partial loss }\end{array}$ & $\begin{array}{l}\text { - Sudden loss of hearing } \\
\text { (bi- or unilateral) }\end{array}$ \\
\hline
\end{tabular}

Tabela I. Objawy neurologiczne, okulistyczne i laryngologiczne u pacjenta z kiłą, które wymagają pogłębionej diagnostyki

\begin{tabular}{|c|c|c|c|}
\hline Objawy neurologiczne & Objawy psychiatryczne & Objawy okulistyczne & Objawy laryngologiczne \\
\hline $\begin{array}{l}\text { • Uporczywe bóle głowy, } \\
\text { zwłaszcza poranne, związane } \\
\text { z nudnościami i wymiotami } \\
\text { • Zaburzenia równowagi } \\
\text { •Zaburzenia czucia }\end{array}$ & $\begin{array}{l}\text { - Szybko postępujący zespół } \\
\text { otępienny }\end{array}$ & $\begin{array}{l}\text { - Nagłe zaniewidzenie, w tym } \\
\text { polowicze }\end{array}$ & $\begin{array}{l}\text { - Nagła utrata słuchu } \\
\text { (obu- lub jednostronna) }\end{array}$ \\
\hline
\end{tabular}

Table 2. Indications for cerebrospinal fluid tests in patients with syphilis

\begin{tabular}{|c|c|c|}
\hline Highly recommended & Recommended & To consider \\
\hline $\begin{array}{l}\text { - Patients with symptoms: } \\
\text { - neurological } \\
\text { - psychiatric } \\
\text { - ophthalmic } \\
\text { - laryngological }\end{array}$ & $\begin{array}{l}\text { - Patients with no: } \\
\text { - neurological } \\
\text { - psychiatric } \\
\text { - ophthalmic } \\
\text { - laryngological symptoms } \\
\text { and } \\
\text { - Improper serological response to } \\
\text { treatment }\end{array}$ & $\begin{array}{l}\text { - Within a year of observations after } \\
\text { the treatment of - early syphilis, the } \\
\text { nontreponemal test titre remains } \\
\text { at }>1 / 4\end{array}$ \\
\hline $\begin{array}{l}\text { - Patients with no: } \\
\text { - neurological } \\
\text { - psychiatric } \\
\text { - ophthalmic } \\
\text { - laryngological symptoms } \\
\text { and } \\
\text { - Tertiary syphilis (i.e. gummatous syphilis } \\
\text { or cardiovascular syphilis) }\end{array}$ & $\begin{array}{l}\text { - Within a year of observations after } \\
\text { the treatment of late syphilis, the } \\
\text { nontreponemal test titre remains at } \\
>1 / 4\end{array}$ & \\
\hline
\end{tabular}

Tabela 2. Wskazania do badania płynu mózgowo-rdzeniowego u pacjentów z kiłą

\begin{tabular}{|c|c|c|}
\hline Wysoce rekomendowane & Rekomendowane & Można rozważyć \\
\hline $\begin{array}{l}\text { - Pacjenci z objawami: } \\
\text { - neurologicznymi } \\
\text { - psychiatrycznymi } \\
\text { - okulistycznymi } \\
\text { - laryngologicznymi }\end{array}$ & $\begin{array}{l}\text { - Pacjenci bez objawów: } \\
\text { - neurologicznych } \\
\text { - psychiatrycznych } \\
\text { - okulistycznych } \\
\text { - laryngologicznych } \\
\text { i Nieprawidłowa odpowiedź serologiczna } \\
\text { na leczenie }\end{array}$ & $\begin{array}{l}\text { - Stale utrzymujące się miano odczynu } \\
\text { niekrętkowego o wartości > I/4 podczas } \\
\text { roku obserwacji po leczeniu kiły wczesnej }\end{array}$ \\
\hline $\begin{array}{l}\text { - Pacjenci bez objawów: } \\
\text { - neurologicznych } \\
\text { - psychiatrycznych } \\
\text { - okulistycznych } \\
\text { - laryngologicznych } \\
\text { - Kiła III okresu (tj. kiła kilakowata lub kiła } \\
\text { układu sercowo-naczyniowego) }\end{array}$ & $\begin{array}{l}\text { - Stale utrzymujące się miano odczynu } \\
\text { niekrętkowego o wartości > I/4 } \\
\text { w czasie roku obserwacji po leczeniu kiły } \\
\text { późnej }\end{array}$ & \\
\hline
\end{tabular}


Table 3. A set of tests that must be performed mandatorily in cerebrospinal fluid

- VDRL (only!)

- TPHA (or another treponemal test, but not FTA)

- Mononuclear cell count in I $\mathrm{mm}^{3}$ (best manually)

- Protein concentration

- Glucose concentration
Tabela 3. Zestaw badań, które należy obowiązkowo wykonać w płynie mózgowo-rdzeniowym

-VDRL (wyłącznie!)

- TPHA (lub inny odczyn krętkowy, ale nie FTA)

- Liczba komórek jednojądrowych w I mm³ (najlepiej manualnie)

- Stężenie białka

- Stężenie glukozy

wym w płynie mózgowo-rdzeniowym jest wyłącznie VDRL [7, 8] (tab. 3).

\section{Rozpoznanie}

Podejrzenie kiły OUN można wysunąć wyłącznie u pacjenta, u którego stwierdzono dodatnie odczyny serologiczne krwi w kierunku kiły [1-3, 5, 6, 9].

$\mathrm{W}$ tabeli 4 przedstawiono kryteria rozpoznania kiły OUN $[3,5,6]$.

\section{Kontrola po leczeniu [2, 10-12]}

Remisja objawów klinicznych jest dobrym parametrem prawidłowej odpowiedzi na leczenie kiły OUN.

Table 4. Criteria for diagnosing central nervous system (CNS) syphilis

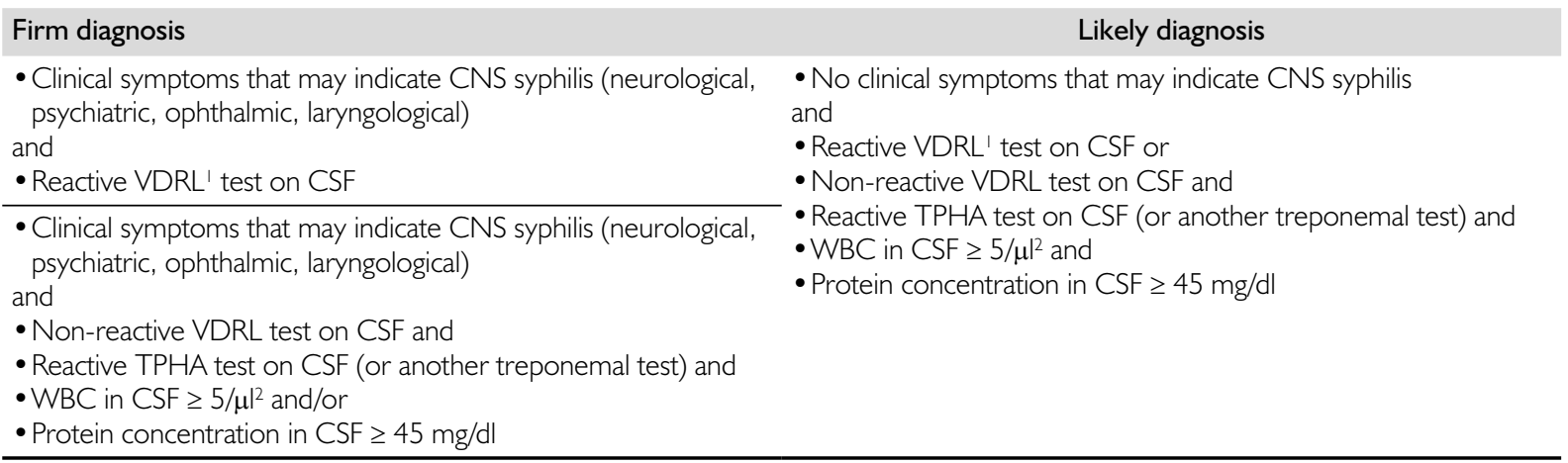

WBC - white blood count; leukocytes; CSF - cerebrospinal fluid. 'If cerebrospinal fluid was not contaminated with blood while being drawn, ${ }^{2} \geq 20 / \mu$ in case of HIV-positive patients [9].

Tabela 4. Kryteria rozpoznania kily ośrodkowego układu nerwowego (OUN)

\begin{tabular}{|c|c|}
\hline Rozpoznanie pewne & Rozpoznanie prawdopodobne \\
\hline $\begin{array}{l}\text { - Objawy kliniczne mogące odpowiadać kile OUN } \\
\text { (neurologiczne, psychiatryczne, okulistyczne, laryngologiczne) } \\
\text { - Reaktywny odczyn VDRL' w PMR }\end{array}$ & \multirow{2}{*}{$\begin{array}{l}\text { - Brak objawów klinicznych mogących odpowiadać kile OUN } \\
\text { i } \\
\text { - Reaktywny odczyn VDRL' w PMR lub } \\
\text { - Niereaktywny odczyn VDRL w PMR oraz } \\
\text { - Reaktywny odczyn TPHA w PMR (lub inny krętkowy) oraz } \\
\text { - WBC w PMR } \geq 5 /\left.\mu\right|^{2} \text { oraz } \\
\text { - Stężenie białka w PMR } \geq 45 \text { mg/dl }\end{array}$} \\
\hline $\begin{array}{l}\text { - Objawy kliniczne mogące odpowiadać kile OUN } \\
\text { (neurologiczne, psychiatryczne, okulistyczne, laryngologiczne) } \\
\text { - } \\
\text { - Reakeaktywny odczyn VDRL w PMR oraz } \\
\text { - WBC w PMR } \geq 5 /\left.\mu^{2}\right|^{2} / / \text { lub } \\
\text { - Stężenie białka w PMR } \geq 45 \text { mg/dl }\end{array}$ & \\
\hline
\end{tabular}

WBC - leukocyty; PMR - płyn mózgowo-rdzeniowy. 'Przy braku zanieczyszczenia płynu mózgowo-rdzeniowego krwiq podczas pobierania, ${ }^{2} \geq 20 / \mu l$ w przypadku pacjentów HIV-pozytywnych [9]. 
to CNS syphilis treatment. Normalization of protein concentration in cerebrospinal fluid happens more slowly (even after 3-4 years) what makes making optimal clinical decisions difficult. In most cases VDRL reaction in cerebrospinal fluid remains positive and is irrelevant in follow-ups after the treatment. A cerebrospinal fluid follow-up test should be performed after 6 months after the treatment. In case pleocytosis (increased leucocyte count in cerebrospinal fluid) persists during follow-ups, the treatment should be repeated. A subsequent cerebrospinal fluid test and a possible repeated treatment should be performed at 6-month intervals.

\section{Treatment}

Table 5 presents therapeutic regimens for central nervous system syphilis.

Treatment of CNS syphilis should be performed only in university venereology centres that have proper experience and diagnostic base. There is no sufficient scientific evidence that drugs other than penicillin are successful in treating CNS syphilis.

Crystalline penicillin as compared with benzathine benzylpenicillin (Debecillin) permeates into the CNS. Standard period of therapy for CNS syphilis with crystalline penicillin amounts to 14 days. In such a case the time for treponemocidal concentration of crystalline penicillin is sufficient if a patient remains in early stages of syphilis. In case of late syphilis, when the period for treponemocidal activity of the drug should not be shorter than 4 weeks as it was mentioned before, 14-day intravenous treatment is insufficient. Whereby, it is recommended to administer intramuscularly additional doses of long acting penicillin.

Table 6 presents an optimal way of treatment after standard CNS syphilis treatment with crystalline penicillin.

\section{SYPHILIS IN PREGNANCY AND CONGENITAL SYPHILIS}

This chapter presents chosen issues connected with diagnostic procedures and treatment regimens

Table 5. Therapeutic schemes in the central nervous system syphilis

\begin{tabular}{l}
\hline First-line treatment \\
\hline - Benzyl penicillin (crystalline; sodium or potassium) \\
I8-24 million U/day i.v. in divided doses every 4 hours \\
for 10-14 days \\
\hline Alternative treatment \\
- Desensitization \\
- Ceftriaxone \\
\hline
\end{tabular}

Normalizacja liczby leukocytów w płynie mózgowo-rdzeniowym jest dobrym markerem laboratoryjnym odpowiedzi na terapię kiły OUN. Normalizacja stężenia białka w płynie mózgowo-rdzeniowym następuje wolniej (nawet po 3-4 latach), co utrudnia podejmowanie optymalnych decyzji klinicznych. Reaktywny odczyn VDRL w płynie mózgowo-rdzeniowym w większości przypadków pozostaje długo dodatni i nie ma znaczenia w kontroli po leczeniu. Kontrolne badanie płynu mózgowo-rdzeniowego po leczeniu należy wykonać po 6 miesiącach. W przypadku utrzymującej się w badaniu kontrolnym pleocytozy (zwiększona liczba leukocytów jednojądrzastych w płynie mózgowo-rdzeniowym) leczenie powinno się powtórzyć. Kolejne badanie płynu i ewentualne powtarzanie terapii należy przeprowadzać w odstępach 6-miesięcznych.

\section{Leczenie}

W tabeli 5 przedstawiono schematy terapeutyczne w kile OUN.

Leczenie kiły OUN powinno być prowadzone wyłącznie w klinicznych ośrodkach dermatologiczno-wenerologicznych, które mają odpowiednie doświadczenie i zaplecze diagnostyczne. Brakuje wystarczających dowodów naukowych na skuteczność w kile OUN innych leków niż penicylina.

Penicylina krystaliczna w porównaniu z penicyliną benzatynową (Debecyliną) przenika do OUN. Standardowy czas terapii kiły OUN penicyliną krystaliczną wynosi 14 dni. Czas trwania krętkobójczego stężenia penicyliny krystalicznej w takim przypadku jest wystarczający, jeśli pacjent jest w okresie kiły wczesnej. W przypadku kiły późnej, gdzie - jak wspomniano - okres krętkobójczego działania leku powinien być nie krótszy niż 4 tygodnie, 14-dniowe leczenie dożylne jest niewystarczające. Zaleca się podanie domięśniowo dodatkowych dawek długo działającej penicyliny.

W tabeli 6 przedstawiono optymalny sposób postępowania leczniczego po standardowym leczeniu kiły OUN penicyliną krystaliczną.

Tabela 5. Schematy terapeutyczne w kile ośrodkowego układu nerwowego

\begin{tabular}{l}
\hline Leczenie I wyboru \\
\hline - Penicylina benzylowa (krystaliczna; sól sodowa lub potasowa) \\
I8-24 mln j./dobę i.v. w dawkach podzielonych co 4 godziny \\
przez 10-14 dni \\
\hline Leczenie alternatywne \\
- Odczulanie \\
- Ceftriakson \\
\hline
\end{tabular}


Table 6. Regimen for further treatment after standard treatment for CNS syphilis with crystalline penicillin

\begin{tabular}{|c|c|c|}
\hline \multicolumn{3}{|l|}{$\begin{array}{l}\text { A patient with CNS syphilis } \\
\text { and }\end{array}$} \\
\hline $\begin{array}{l}\text { - Early syphilis treated with i.v. crystalline } \\
\text { penicillin for } 10 \text { days }\end{array}$ & $\begin{array}{l}\text { - Early syphilis treated with i.v. crystalline } \\
\text { penicillin for } 14 \text { days }\end{array}$ & $\begin{array}{l}\text { - Late syphilis treated with i.v. crystalline } \\
\text { penicillin for 10-14 days }\end{array}$ \\
\hline \multicolumn{3}{|c|}{ After the treatment for CNS syphilis was discontinued } \\
\hline $\begin{array}{l}\text { - Benzathine benzylpenicillin } 2.4 \mathrm{mln} \text { units } \\
\text { i.m. once from the next day when } \\
\text { i.v. treatment was discontinued }\end{array}$ & - No further treatment required & $\begin{array}{l}\text { - Benzathine benzylpenicillin } 2.4 \text { mln units } \\
\text { i.m. once from the next day when } \\
\text { i.v. treatment was discontinued' }\end{array}$ \\
\hline $\begin{array}{l}\text { - Procaine penicillin } 0.6 \mathrm{mln} \text { units i.m. } \\
\text { once a day from the next day when } \\
\text { i.v. treatment was discontinued for } \\
\text { subsequent } 4 \text { days }\end{array}$ & & \\
\hline
\end{tabular}

'Some experts recommend two i.m. injection of benzathine benzylpenicillin each with $2.4 \mathrm{~m} / \mathrm{n}$ units at a week intervals [6].

Tabela 6. Schemat dalszego postępowania leczniczego po standardowym leczeniu kity OUN penicyliną krystaliczną

\begin{tabular}{|c|c|c|}
\hline \multicolumn{3}{|l|}{$\begin{array}{l}\text { Pacjent z kiłą OUN } \\
\text { oraz }\end{array}$} \\
\hline $\begin{array}{l}\text { - Kitą wczesną leczony i.v. penicyliną } \\
\text { krystaliczną przez I0 dni }\end{array}$ & $\begin{array}{l}\text { - Kitą wczesną leczony i.v. penicyliną } \\
\text { krystaliczną przez I } 4 \text { dni }\end{array}$ & $\begin{array}{l}\text { - Kiłą późną leczony i.v. penicyliną } \\
\text { krystaliczną przez 10-14 dni }\end{array}$ \\
\hline \multicolumn{3}{|l|}{ Po zakończeniu leczenia kiły OUN } \\
\hline $\begin{array}{l}\text { - Penicylina benzatynowa 2,4 mln j. i.m. } \\
\text { jednorazowo w następnym dniu } \\
\text { po zakończeniu leczenia i.v. } \\
\text { lub } \\
\text { - Penicylina prokainowa 0,6 mln j. i.m. raz } \\
\text { dziennie od kolejnego dnia po zakończeniu } \\
\text { leczenia i.v. przez } 4 \text { kolejne dni }\end{array}$ & - Nie wymaga dalszego leczenia & $\begin{array}{l}\text { - Penicylina benzatynowa } 2,4 \text { mln j. i.m. } \\
\text { jednorazowo w następnym dniu } \\
\text { po zakończeniu leczenia i.v. }\end{array}$ \\
\hline
\end{tabular}

'Niektórzy eksperci zalecajq dwie domięśniowe iniekcje penicyliny benzatynowej każda po 2,4 mln j. w odstępach tygodniowych [6].

for syphilis in pregnancy. In the majority of cases, diagnosing and treating the pregnant suffering from syphilis do not differ from recommended ways for other patients.

\section{General comments}

The highest risk of congenital syphilis regards children whose mothers suffered from early syphilis while being pregnant.

The risk for infecting the foetus appears also in cases when a pregnant woman suffered from late syphilis, even in cases when the nontreponemal test titre was low.

Figure 1 presents a treatment regimen for a pregnant woman and additional positive blood serological tests for syphilis.

Treatment of syphilis in the pregnant, especially in the second and third trimester, may be associated with premature delivery. It is a rare complication that stems from cytokine Jarisch-Herxheimer reaction.

A treated pregnant woman should be informed in detail about the necessary and immediate consultation

\section{KIŁA U KOBIET W CIAZŻY I KIŁA WRODZONA}

W niniejszym rozdziale przedstawiono wybrane zagadnienia dotyczace postępowania diagnostycznego i leczniczego w kile u kobiet w ciąży. Diagnostyka i leczenie kobiet ciężarnych chorych na kiłę w większości przypadków nie różni się od sposobów rekomendowanych dla pozostałej grupy pacjentów.

\section{Uwagi ogólne}

Największe ryzyko wystąpienia kiły wrodzonej dotyczy dzieci, których matki chorowały w ciąży na kiłę wczesną.

Ryzyko zakażenia płodu występuje także w przypadkach, gdy kobieta ciężarna choruje na kiłę późną, nawet jeśli stwierdzone u niej miano odczynu niekrętkowego jest niskie.

Na rycinie 1 przedstawiono schemat postępowania $\mathrm{u}$ kobiet $\mathrm{w}$ ciąży z dodatnimi wynikami badań serologicznych krwi w kierunku kiły.

Leczenie kiły u kobiety w ciąży, zwłaszcza w drugim i trzecim trymestrze, może wiązać się z ryzykiem 


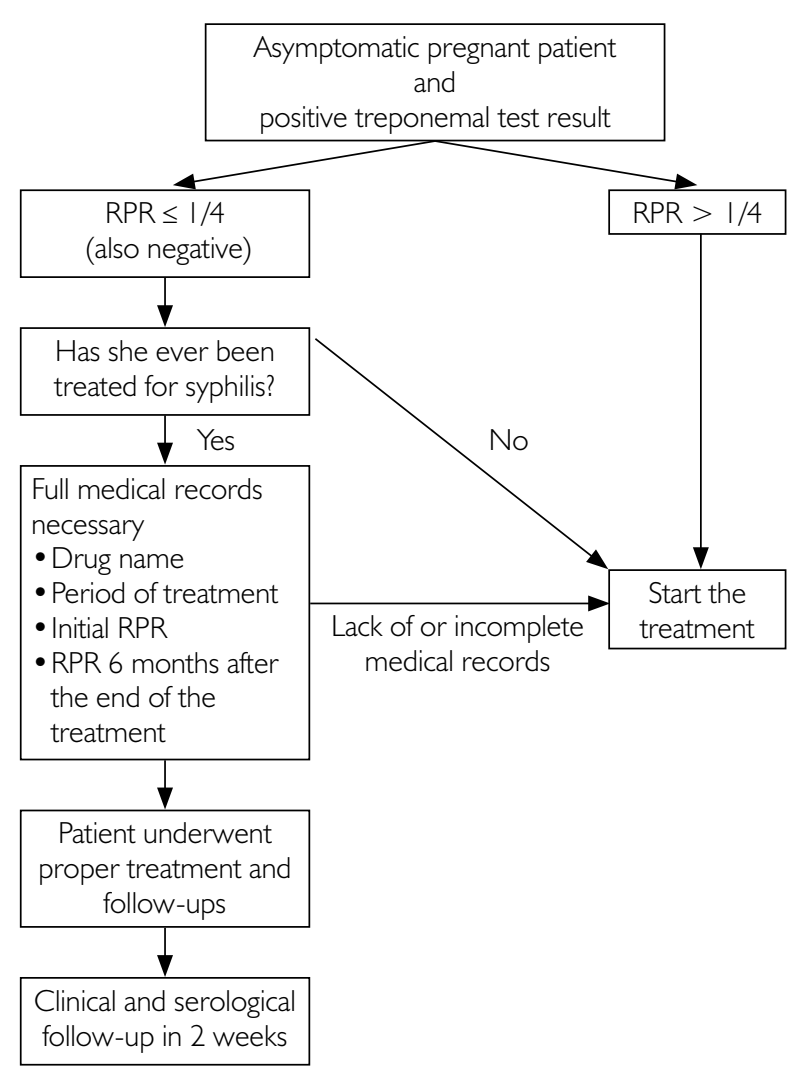

Figure I. Procedures to follow in case a pregnant patient has positive blood serological test results for syphilis

with an obstetrix in case uterine contractions appear or foetal movements are less frequent or dwindle.

Evaluation of proper clinical response to treatment of the pregnant should, first and foremost, regard remission of clinical symptoms. Evaluation of serological response to treatment is difficult as most patients give birth before the nontreponemal test titre is lowered to an appropriate level.

Table 7 presents clinical situations in which, despite the treatment, it should be concluded that it was not sufficient and the neonate should undergo prophylactic treatment.

A partner of the pregnant patient who was diagnosed with syphilis should undergo a procedure presented in Figure 5 (part 1 of recommendation).

Table 7. Clinical situation in which treatment undertaken in pregnancy is insufficient. A neonate should undergo prophylactic treatment

- The delivery took place within 30 day from the date of treatment discontinuation

- Upon delivery date, the patient showed clinical symptoms of an infection with syphilis

- Upon delivery date, the nontreponemal test titre of the patient was four times higher (i.e. 2 dilutions) as compared with her previous result

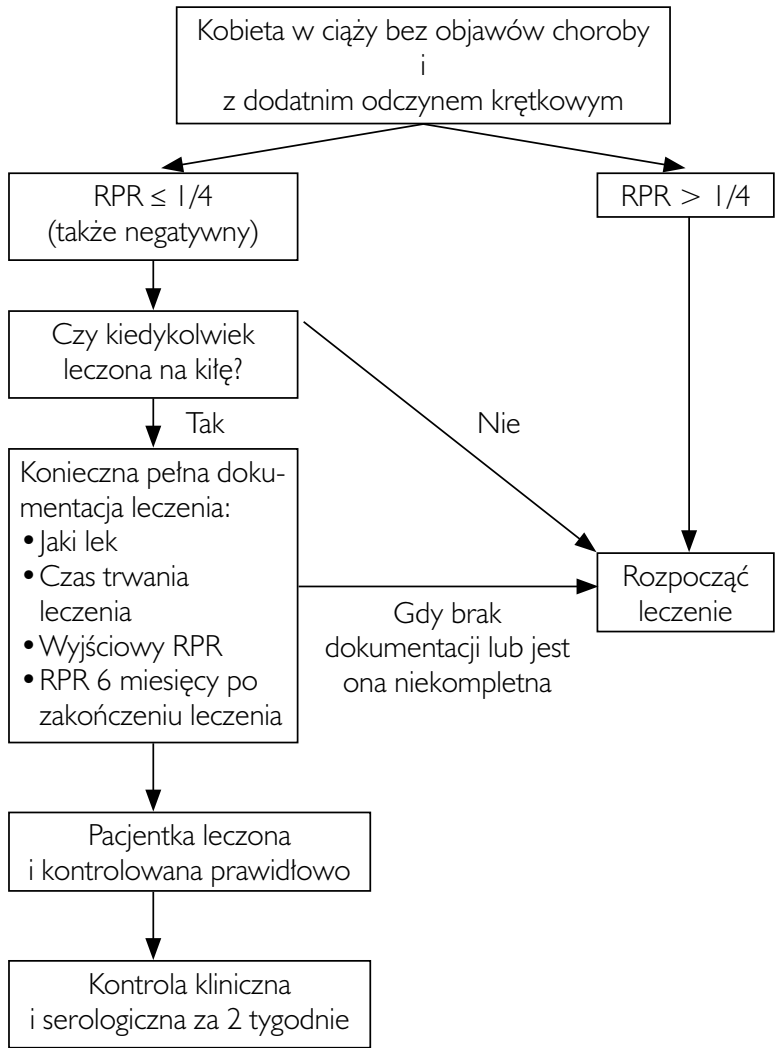

Rycina I. Schemat postępowania z kobietą w ciąży z dodatnimi wynikami badań serologicznych krwi w kierunku kiły

porodu przedwczesnego. Jest to rzadkie powikłanie leczenia, u którego podłoża leży cytokinowa reakcja Jarischa-Herxheimera-Łukasiewicza.

Poddaną leczeniu kobietę ciężarną należy szczegółowo poinformować o konieczności niezwłocznej konsultacji położniczej w przypadku wystąpienia skurczów macicy lub zmniejszenia częstości odczuwania albo zaniku ruchów płodu.

Ocena prawidłowej odpowiedzi na leczenie kobiety w ciąży powinna przede wszystkim dotyczyć remisji objawów klinicznych. Ocena serologiczna odpowiedzi na leczenie jest trudna, gdyż większość pacjentek urodzi, zanim dojdzie do odpowiedniego obniżenia miana odczynu niekrętkowego.

Tabela 7. Sytuacje kliniczne, w których podjęte w ciąży leczenie jest niewystarczające. Dziecko należy leczyć profilaktycznie

- Poród nastąpił w czasie 30 dni od zakończenia terapii

-W dniu porodu u pacjentki stwierdzono objawy kliniczne zakażenia kiłą

-W dniu porodu miano odczynu niekrętkowego było u pacjentki 4-krotnie wyższe (tj. 2 rozcieńczenia)

w porównaniu z ostatnim wynikiem 
It is recommended that a delivery of the child, whose mother was treated for syphilis during pregnancy, should take place in a perinatological centre, in which blood serological tests such as RPR, TPHA, and IgM anti-treponema pallidum, may be performed apart from basic analytical tests.

The neonate should not be discharged from the neonatal ward prior to receiving serological test results and undergoing a consultation with a dermatology and venereology specialist.

Low nontreponemal test titre $(\leq 1 / 4)$ may also be indicative of an early stage of infection. Thereby, if the patient was previously treated and an analysis of medical records allows for stating that the treatment and follow-up were conducted properly, a follow-up serological test in 2 weeks time should be recommended. Then, it may be possible to eliminate, with a high likelihood, an early period of the infection. If upon follow-up, the nontreponemal test titre remains at the same level, the results may be regarded as typical for past treated syphilis. The patient should undergo serological follow-ups at a month intervals. If, at any stage of follow-ups, there appears at least fourfold increase in the nontreponemal test titre as compared with previous value, treatment should be commenced immediately.

After treating syphilis in a pregnant patient, serological response should be estimated regularly at a month intervals. Blood for serological tests should also be saved upon delivery.

Figure 2 presents a procedure for a neonate, in whose mother positive serological test results for syphilis were confirmed.

In neonates, venous blood should be taken for tests, and not umbilical cord blood. Cerebrospinal fluid tests in neonates are indicated when: 1) there are abnormalities in physical examination or laboratory tests suggest congenital syphilis, 2) the RPR titre in a neonate was confirmed to be four times higher than in the mother or there are positive IgM anti-T. pallidum antibodies, and 3) the neonate's mother was treated improperly or insufficiently. If the leucocyte count in neonate's cerebrospinal fluid $\geq 5 / \mu \mathrm{l}$ and/or protein concentration exceeds $40 \mathrm{mg} / \mathrm{dl}$, the test should be repeated in 3 months. If abnormalities in the cerebrospinal fluid test persist, i.v. treatment should be performed again [13-17].

\section{Follow-up regimen in children with positive serological test results not qualified for treatment}

Treponemal tests should not be used to perform a serological examination of children delivered by syphilitic mothers. Antibodies detected in such tests are passively transmitted by placenta, and they
W tabeli 7 przedstawiono sytuacje kliniczne, w których mimo podjęcia leczenia należy uznać, że było ono niewystarczające i u dziecka powinno się wdrożyć leczenie profilaktyczne.

U partnera kobiety w ciąży, u której rozpoznano kiłę, należy wdrożyć odpowiednią procedurę (część 1. rekomendacji, ryc. 5).

Zaleca się, aby poród dziecka, którego matka była leczona w czasie ciąży na kiłę, odbył się w ośrodku perinatologicznym, w którym możliwe będzie wykonanie, oprócz podstawowych badań analitycznych, także odczynów serologicznych krwi, takich jak RPR, TPHA, anty-Treponema pallidum IgM.

Dziecko nie powinno być wypisane $\mathrm{z}$ oddziału neonatologii przed uzyskaniem wyników badań serologicznych i konsultacją specjalisty dermatologa-wenerologa.

Niskie miano odczynu niekrętkowego $(\leq 1 / 4)$ może świadczyć również o wczesnym okresie zakażenia. Jeśli pacjentka była wcześniej leczona, a analiza dokumentacji medycznej pozwala na ustalenie, że leczenie i kontrolę przeprowadzono poprawnie, należy zalecić kontrolne badanie serologiczne za 2 tygodnie. Możliwe będzie wówczas wykluczenie z dużym prawdopodobieństwem wczesnego okresu zakażenia. Jeżeli w kontroli miano odczynu niekrętkowego utrzymuje się na tym samym poziomie, wyniki można uznać za typowe dla przebytej, leczonej kiły. Pacjentkę należy następnie poddać kontrolom serologicznym w odstępach miesiąca. Jeśli na którymkolwiek etapie kontroli dojdzie do co najmniej 4-krotnego wzrostu miana odczynu niekrętkowego w porównaniu z poprzednią wartością, powinno się niezwłocznie rozpocząć leczenie.

Po leczeniu kiły u kobiety ciężarnej należy oceniać odpowiedź serologiczną regularnie w odstępach miesięcznych. Krew do badań serologicznych powinno się także zabezpieczyć $\mathrm{w}$ dniu porodu.

Na rycinie 2 przedstawiono schemat postępowania z noworodkiem, u którego matki stwierdzono dodatnie odczyny serologiczne w kierunku kiły.

Do badań serologicznych u noworodków należy pobierać krew żylną, niepępowinową. Badanie płynu mózgowo-rdzeniowego u noworodków jest wskazane w przypadku: 1) odchyleń w badaniu fizykalnym lub badaniach laboratoryjnych sugerujących rozpoznanie kiły wrodzonej, 2) obecności u dziecka miana odczynu RPR 4-krotnie wyższego niż u matki lub dodatnich przeciwciał anty-T. pallidum w klasie IgMi3) gdy matka dziecka była leczona nieprawidłowo lub niewystarczająco. Jeżeli liczba leukocytów w płynie mózgowo-rdzeniowym noworodka wynosi $\geq 5 / \mu \mathrm{l}$ //lub stężenie białka przekracza $40 \mathrm{mg} / \mathrm{dl}$, badanie należy powtórzyć za 3 miesiące. Jeśli nieprawidłowości w badaniu płynu mózgowo-rdzeniowego nadal się utrzymują, powinno się przeprowadzić ponowne leczenie dożylne [13-17]. 


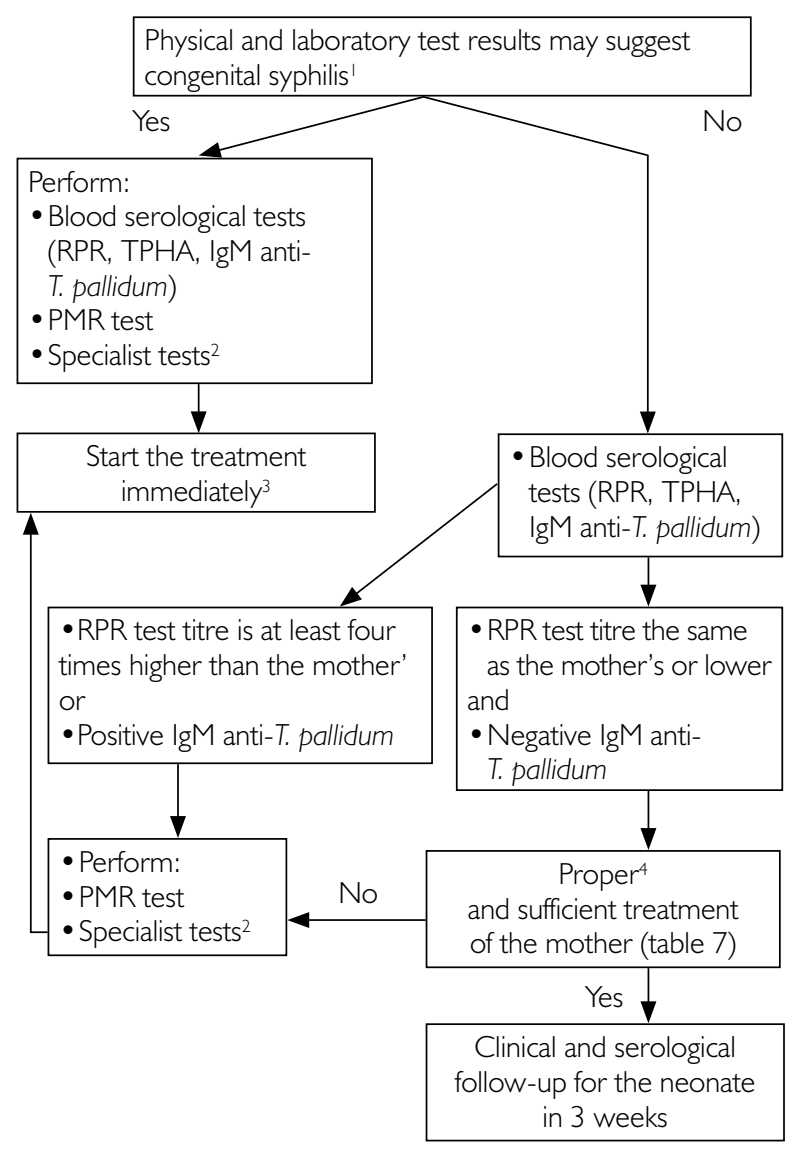

'Table 8 catalogues laboratory test results and deviations in physical examination that may indicate congenital syphilis.

${ }^{2}$ Table 9 shows a set of specialist tests that need to be performed in a neonate.

${ }^{3}$ Recommended regimen in benzathine benzylpenicillin (crystalline)

150,000 units/kg b.w./day i.v. in 6 divided doses, i.e. every 4 hours for 14 days Incorrect treatment of the mother includes treatment with antibiotics other than penicillin or too short treatment with penicillin (e.g. crystalline penicillin

i.v. or procaine penicillin i.m. for 10 days).

Figure 2. Procedures for a neonate whose mother was confirmed to have positive blood serological test results for syphilis

Table 8. Laboratory test results and abnormalities in physical examination that may be indicative of congenital syphilis

\section{Laboratory tests}

- Haemolytic anaemia

- Thrombocytopenia

- Increased activity of transaminases

in blood serum

- Active sediment in urine

(dysmorphic erythrocytes,

proteinuria)

Table 9. A set of specialist tests that should be performed in a neonate with a suspected congenital syphilis

- Long bones X-ray

- Chest X-ray

- Brain imaging

- Ophthalmic examination

- Audiometry

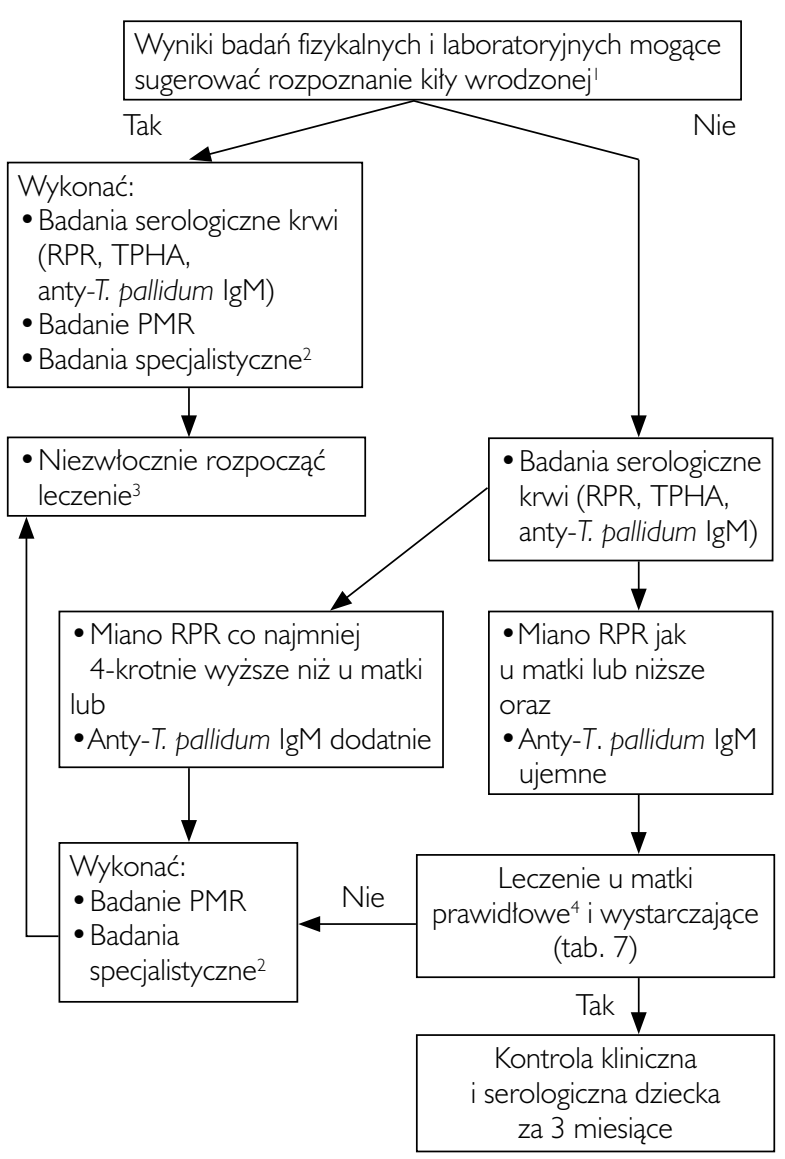

'W tabeli 8 zestawiono wyniki badań laboratoryjnych i odchylenia w badaniu fizykalnym, które mogq świadczyć o kile wrodzonej.

${ }^{2} \mathrm{~W}$ tabeli 9 przedstawiono zestaw badań specjalistycznych, które należy przeprowadzić u dziecka.

${ }^{3}$ Rekomendowany schemat to penicylina benzylowa (krystaliczna)

150000 j./kg m.c./dobę i.v. w 6 dawkach podzielonych, tj. co 4 godziny przez

14 dni.

${ }^{4}$ Nieprawidłowe leczenie matki stanowi przede wszystkim terapia antybiotykami innymi niż penicylina lub zbyt krótkie leczenie penicylina (np. penicylina krystaliczna i.v. lub penicylina prokainowa i.m. przez 10 dni).

Rycina 2. Schemat postępowania z noworodkiem, u którego matki stwierdzono dodatnie odczyny serologiczne krwi w kierunku kiły

Tabela 8. Wyniki badań laboratoryjnych i odchylenia $w$ badaniu fizykalnym, które mogą świadczyć o kile wrodzonej

\begin{tabular}{lc} 
Badania laboratoryjne & Badanie fizykalne \\
- Anemia hemolityczna & $\bullet$ Hepatosplenomegalia \\
- Małopłytkowość & $\bullet$ Zmiany skórne \\
- Podwyższona aktywność & i śluzówkowe \\
transaminaz w surowicy & • Porażenie rzekome \\
- Aktywny osad moczu (erytrocyty & Parrota \\
wyługowane, białkomocz) & \\
\hline
\end{tabular}

Tabela 9. Zestaw badań specjalistycznych, które należy przeprowadzić u noworodka z podejrzeniem kiły wrodzonej

- Badanie radiologiczne kości długich

- Badanie radiologiczne klatki piersiowej

- Obrazowanie mózgowia

- Badanie okulistyczne

- Audiometria 
can disappear from a neonate's blood even after 15 months.

Neonates with a negative nontreponemal test result upon birth should undergo clinical and serological follow-ups in 3 months. The time includes average 90 days of syphilis incubation.

Neonates with positive nontreponemal test results upon birth should undergo clinical and serological follow-ups every 3 months. In the $6^{\text {th }}$ month of live, a negativization of nontreponemal test results is to be expected.

If in the $6^{\text {th }}$ month of a child's life a nontreponemal test result continues to be positive, there is a high likelihood of congenital syphilis. Even if there are no abnormalities in physical examination in the child, cerebrospinal fluid and specialised tests should be performed (table 9) and treatment should be introduced immediately [13-17].

\section{CONFLICT OF INTEREST}

The authors declare no conflict of interest.

\section{Postępowanie kontrolne u dzieci z dodatnimi odczynami serologicznymi niezakwalifikowanymi do leczenia}

Odczyny krętkowe nie powinny być wykorzystywane do oceny serologicznej dzieci urodzonych przez matki chore na kiłę. Wykrywane w tych odczynach przeciwciała są biernie przenoszone przez łożysko, a ich zanik w krwi dziecka może trwać nawet 15 miesięcy.

Dzieci z ujemnym przy porodzie odczynem niekrętkowym należy skontrolować klinicznie i serologicznie za 3 miesiące. Czas ten uwzględnia średnio 90-dniowy okres inkubacji kiły.

Dzieci z dodatnimi odczynami niekrętkowymi przy porodzie powinno sie oceniać klinicznie i serologicznie co 3 miesiące. W 6. miesiącu życia należy spodziewać się negatywizacji odczynu niekrętkowego.

Jeżeli w 6. miesiącu życia dziecka odczyn niekrętkowy jest nadal dodatni, istnieje wysokie prawdopodobieństwo kiły wrodzonej. Nawet jeżeli u dziecka nie stwierdza się odchyleń w badaniu fizykalnym, powinno się wykonać badanie płynu mózgowo-rdzeniowego, badania specjalistyczne (tab. 9) i niezwłocznie wdrożyć leczenie [13-17].

\section{KONFLIKT INTERESÓW}

Autorzy nie zgłaszają konfliktu interesów.

\section{References}

\section{Piśmiennictwo}

1. Marra C.M.: Neurosyphilis. Curr Neurol Neuroscien Rep 2004, 4, 435-440.

2. Ghanem K.G.: Neurosyphilis: a historical perspective and review. CNS Neurosc Ther 2010, 16, e157-e168.

3. Dabis R., Radcliffe K.: What is the role of a full physical examination in the management of asymptomatic patients with late syphilis. Int J STD AIDS 2012, 23, 901-902.

4. Pastuszczak M., Jakiela B., Wielowieyska-Szybinska D., Jaworek A.K., Zeman J., Wojas-Pelc A.: Elevated cerebrospinal fluid interleukin-17A and interferon-gamma levels in early asymptomatic neurosyphilis. Sex Transm Dis 2013, 40, 808-812.

5. French P., Gomberg M., Janier M., Schmidt B., van Voorst Vader P., Young H.: IUSTI: 2008 European guideline on the management of syphilis. Int J STD AIDS 2009, 20, 300-309.

6. Centers for Disease Control and Prevention.: Sexually Transmitted Diseases Treatment Guidelines. MMWR 2010, 59, No. RR-12.

7. Jaffe H.W., Larsen S.A., Peters M., Jove D.F., Lopez B., Schroeter A.L.: Tests for treponemal antibody in CSF. Arch Intern Med 1978, 138, 252-255.

8. Marra C.M., Tantalo L.C., Maxwell C.L., Ho E.L., Sahi S.K., Jones T.: The RPR test cannot replace the VDRL test for neurosyphilis diagnosis. Sex Transm Dis 2012, 39, 453-457.

9. Marra C.M., Maxwell C.L., Smith S.L., Lukehart S.A., Rompalo A.M., Eaton M., et al.: Cerebrospinal fluid abnormalities in patients with syphilis: association with clinical and laboratory features. J Infect Dis 2004, 189, 369-376.

10. Marra C.M., Maxwell C.L., Tantalo L., Eaton M., Rompalo A.M., Raines C., et al.: Normalization of cerebrospinal fluid abnormalities after neurosyphilis therapy: does HIV status matter? Clin Infect Dis 2004, 38, 1001-1006.

11. Marra C.M., Maxwell C.L., Tanalo L.C., Sahi S.K., Lukehart S.A.: Normalization of serum rapid plasma reagin titer predicts normalization of cerebrospinal fluid and clinical abnormalities after treatment of neurosyphilis. Clin Infect Dis 2008, 47, 893899.

12. Lukehart S.A., Hook E.W. III, Baker-Zander S.A., Coller A.C., Critchlow C.W., Handsfield H.H.: Invasion of the central nervous system by Treponema pallidum: implications for diagnosis and treatment. Ann Intern Med 1988, 109, 855-862. 
13. Wendel G.D., Sheffield J.S., Holler L.M., Hill J.B., Ramsey P.S., Sanchez P.J.: Treatment of syphilis in pregnancy and prevention of congenital syphilis. Clin Infect Dis 2010, 35, S200-S209.

14. Nathan L., Bawdon R.E., Sidawi J.E., Stettler R.W., McIntire D.M., Wendel G.D. Jr.: Penicillin levels following the administration of benzathine penicillin G in pregnancy. Obst Gynecol 1993, 82, 338-342.

15. Newman L., Kamb M., Hawkes S., Gomez G., Say L., Seuc A., et al.: Global estimates of syphilis in pregnancy and associated adverse outcomes: analysis of multinational antenatal surveillance data. PLoS Med 2013, 10, e1001396.

16. Alexander J.M., Sheffield J.S., Sanchez P.J., Mayfield J., Wendel G.D. Jr.: Efficacy of treatment for syphilis in pregnancy. Obst Gynecol 1999, 93, 5-8.

17. Peterman T.A., Newman D.R., Davis D., Su J.R.: Do women with persistently negative nontreponemal test results transmit syphilis during pregnancy? Sex Transm Dis 2013, 40, 311-315.

Received: 25.05 .2018

Accepted: 11.06 .2018

Otrzymano: 25.05.2018 r.

Zaakceptowano: $11.06 .2018 \mathrm{r}$.

How to cite this article

Wojas-Pelc A., Pastuszczak M., Serwin A.B., Rudnicka I., Majewski S., Czajkowski R., Flisiak I., Placek W., Maj J., Maleszka R., Rudnicka L.: Syphilis. Diagnostic and therapeutic recommendations of the Polish Dermatological Society. Part 2: neurosyphilis, syphilis in pregnancy and congenital syphilis. Dermatol Rev/Przegl Dermatol 2018, 105, 582-592. DOI: https://doi.org/10.5114/dr.2018.79170. 